\title{
Relation of coronary heart disease and apolipoprotein $E$ phenotype in patients with non-insulin dependent diabetes
}

\author{
Markku Laakso, Antero Kesäniemi, Kari Kervinen, Matti Jauhiainen, Kalevi Pyörälä
}

\begin{abstract}
Objectives-To examine the relation between coronary heart disease and the apolipoprotein $\mathbf{E}$ phenotypes in patients with non-insulin dependent diabetes mellitus.

Design-Cross sectional study.

Setting-District around Kuopio University Central Hospital, East Finland.

Subjects-138 men with non-insulin dependent diabetes and 64 men without diabetes as controls.

Main outcome measure-Apolipoprotein E phenotype, electrocardiographic abnormalities, other signs of coronary heart disease.

Results - The prevalences of definite myocardial infarction and ischaemic electrocardiographic changes were highest in the diabetic men with the phenotypes $\mathbf{E} 4 / 4$ or E4/3 (25\% (95\% confidence interval $18 \%$ to $32 \%)$ and $50 \%(42 \%$ to $58 \%)$ respectively), although the difference between the phenotype groups was not significant. The prevalence of angina pectoris was $69 \%(61 \%$ to $77 \%)$ in men with the phenotypes E4/4 or $E 4 / 3$ ( $p=0.005$ compared with other phenotypes), $41 \%$ (33\% to $49 \%)$ in men with phenotype $E 3 / 3$, and $47 \%(39 \%$ to $55 \%)$ in those with phenotypes E2/2 or E2/3. Similarly, the simultaneous presence of angina pectoris and ischaemic electrocardiographic changes was highest in the diabetic men with the phenotypes E4/4 or E4/3 (42\% $v 22 \%$ in those with $\mathrm{E} 3 / 3$ and $29 \%$ in those with E2/2, $E 2 / 3 ; p=0.038$ ). Overall, the prevalence of any evidence of coronary heart disease among the diabetic subjects with the phenotypes E4/4 or E4/3 was $81 \%$ ( $p=0.011$ compared with other phenotypes), $58 \%$ in those with phenotype E3/3, and $53 \%$ in those with phenotypes $E 2 / 2$ or $E 3 / 3$.
\end{abstract}

Conclusion-Apolipoprotein E phenotypes E4/4 and E4/3 modulate the risk of coronary heart disease in men with non-insulin dependent diabetes.

\section{Introduction}

Lipoproteins are important determinants of atherosclerotic vascular disease in man. The serum concentrations and metabolism of lipoproteins are largely modulated by apolipoproteins and it has therefore been hypothesised that genetic variations in apolipoproteins are associated with the variation in the susceptibility to coronary heart disease.' Polymorphism of apolipoprotein $\mathrm{E}$ has recently received an increasing attention. Three common alleles, e2, e3, and e4 determine the six apolipoprotein E phenotypes E2/2, E2/3, E2/4, E3/3, $\mathrm{E} 4 / 3$, and $\mathrm{E} 4 / 4$. Low density lipoprotein metabolism is associated with the apolipoprotein $\mathrm{E}$ polymorphism such that subjects with the phenotypes E4/3 and E4/4 have higher concentrations and subjects with the $\mathrm{e} 2$ allele lower plasma concentrations of total and low density lipoprotein cholesterol than do subjects with the commonest apolipoprotein E phenotype, E3/3.2.5
Diabetic patients, particularly those with non-insulin dependent diabetes, have an increased risk of all manifestations of atherosclerotic vascular disease. ${ }^{6}$ Although non-insulin dependent diabetes has adverse effects on serum lipoproteins and is associated with an increased incidence of hypertension and obesity, the strength of the relation between total cholesterol concentration, blood pressure, and smoking and the risk of coronary heart disease seems to be about the same in people with and without diabetes. ${ }^{6}$ Indeed, the major proportion of the excess of coronary heart disease in non-insulin dependent diabetic patients still remains unexplained.

The Finnish population has an extremely high prevalence of coronary heart disease, and Finland also ranks among those countries with the highest cholesterol concentrations in the world. ${ }^{7}$ Among the Finns men with non-insulin dependent diabetes from East Finland are at a particularly high risk of atherosclerosis; manifestations of coronary heart disease occur two to four times more often among them than in men without diabetes. ${ }^{8}$ Since classic risk factors do not seem to explain this excess risk ${ }^{8}$ we studied the relation between coronary heart disease and apolipoprotein $\mathbf{E}$ phenotypes in men with non-insulin dependent diabetes from East Finland to elucidate the role of the phenotype pattern in modulating the risk of coronary heart disease.

\section{Subjects and methods}

All diabetic patients in Finland needing drugs for diabetes are provided with them free of charge according to the Sickness Insurance Act. The Social Insurance Institution maintains a central register of all the diabetic subjects receiving drug reimbursement. From this register all diabetic subjects aged 45-64 years were identified from the population living in the district of Kuopio University Central Hospital (East Finland). The subjects were originally identified for a study of the prevalence of atherosclerotic vascular disease and its risk factors in subjects with and without diabetes. ${ }^{8}$ For the present study we randomly selected 138 of the 253 men with non-insulin dependent diabetes. All diabetic men included in the final study population fulfilled the World Health Organisation criteria for diabetes mellitus. ${ }^{9}$

We randomly selected 64 men without diabetes, aged 45-64 years, from the population register for the district to serve as controls. The controls were thus completely representative of the non-diabetic population of the study area. Diabetes was excluded in the controls on the basis of measurements of fasting plasma glucose concentration. None of the control or diabetic men were receiving hypolipidaemic drugs and none had a significant impairment in renal function as assessed by serum creatinine concentration. The participation rate in the original study from which 
these men were drawn was $79 \%$ in the control group and $81 \%$ in the diabetic group.

Body mass index was calculated according to the formula weight $(\mathrm{kg}) /$ height $(\mathrm{m})^{2}$. Exercise level was divided into two categories: (a) no or slight physical exercise during leisure time or work and (b) regular physical exercise during leisure time (for example, walking, bicycling, jogging, or swimming for at least 30 minutes at least twice a week) or heavy physical activity at work (for example, heavy industrial work, farming, lumberjacking), or both. Smoking was defined on the basis of current cigarette smoking. Hypertension was defined as the use of antihypertensive drugs or actual systolic blood pressure $>160 \mathrm{~mm} \mathrm{Hg}$ or diastolic blood pressure $>95 \mathrm{~mm} \mathrm{Hg}$. Angina pectoris was evaluated by the Rose cardiovascular questionnaire. $^{10}$

The medical records of all those subjects who reported having been admitted to any hospital because of chest pain were carefully reviewed. We used the WHO criteria for definite myocardial infarction, based on the chest pain symptoms, electrocardiographic changes, and enzyme determinations, to diagnose previous myocardial infarction. ${ }^{11}$ A conventional electrocardiogram was recorded from each subject after a 12 hour fast; Abnormalities were classified according to the Minnesota code. ${ }^{10}$ The statistical analyses concerning the association of apolipoprotein $\mathrm{E}$ phenotypes with coronary heart disease were carried out in the following categories: definite myocardial infarction (definite myocardial infarction verified at hospital or $\mathrm{Q} / \mathrm{QS}$ change on electrocardiography, Minnesota codes 1.1-1.2); ischaemic electrocardiographic changes (ischaemic ST/T changes or left bundle branch block, Minnesota codes 1.1-1.3, 4.1$4.3,5.1-5.3,7.1$ ); angina pectoris; and any evidence of coronary heart disease (definite myocardial infarction or ishaemic electrocardiographic changes or angina pectoris)

\section{LABORATORY TESTS}

Serum lipid and lipoprotein concentrations were determined from fresh serum samples drawn after a 12 hour overnight fast. Lipoprotein fractionation was performed by ultracentrifugation and selective precipitation with a modification ${ }^{12}$ to the method originally described by Havel et $a l^{13}$ as previously reported. ${ }^{14} 15$ Cholesterol and triglycerides concentrations in whole serum and in lipoprotein fractions were assayed by automated enzymatic methods (Boehringer-Mannheim, West Germany). ${ }^{16}$ Serum apolipoprotein AI concentration was determined by a commercial immunochemical method that was based on measuring immunoprecipitation at $340 \mathrm{~nm}$ (Orion Diagnostica, Finland). ${ }^{17}$ Serum apolipoprotein B concentration was determined by electroimmunoassay..$^{18}$ The apolipoprotein $\mathrm{E}$ phenotype was determined from the whole plasma after delipidation by isoelectric focusing and immunoblotting techniques. ${ }^{19} 20$

The concentration of glycated haemoglobin (normal range $5 \cdot 5-8 \cdot 5 \%$; coefficient of variation $6 \%$ ) was determined by commercial column chromatography (Quick-Sep fast haemoglobin test system, Isolab Akron, Ohio, United States) after incubation of blood in $0.9 \%$ saline for 12 hours. Plasma glucose concentration was measured by the glucose dehydrogenase method (Merck Diagnostica, West Germany). Patients' endogenous insulin secretion capacity was assessed after eating by measuring plasma $\mathrm{C}$ peptide concentration after stimulation with $1 \mathrm{mg}$ of intravenous glucagon. ${ }^{21}$ Plasma $C$ peptide was assessed by radioimmunosassay (antiserum M 1230, Novo Industri, Copenhagen, Denmark). ${ }^{22}$ The diagnosis of noninsulin dependent diabetes was based on criteria suggested by the WHO. ${ }^{9}$ In insulin treated patients the $\mathrm{C}$ peptide response to intravenous glucagon was used to classify different types of diabetes. Patients with a C peptide concentration over $0.2 \mathrm{nmol} / \mathrm{l}$ six minutes after $1 \mathrm{mg}$ of glucagon with no history of ketoacidosis were classified as having non-insulin dependent diabetes. Patients with no or low $\mathrm{C}$ peptide response $(<0.20 \mathrm{nmol} / \mathrm{l})$ were diagnosed as having insulin dependent diabetes mellitus ${ }^{23}$ and excluded from the study.

\section{STATISTICAL METHODS}

Results for continuous variables are given as mean (SD) values. Comparisons between more than two groups were done by the analysis of variance. Comparisons between two groups were performed by the $\chi^{2}$ test, Fisher's exact test, or Student's $t$ test for independent samples. Logarithmic transformation of total and very low density lipoprotein triglyceride concentrations were used in all statistical analyses including these variables.

\section{Results}

Table I lists the characteristics of the study groups. Diabetic subjects were heavier, had more hypertension, and were less physically active than the control subjects. Table II gives the frequency of the various apolipoprotein $\mathrm{E}$ phenotypes and the gene frequencies. Although the phenotype E4/3 was somewhat more common among men with non-insulin dependent diabetes, no significant differences between the diabetic and control groups were observed. Correspondingly, gene frequencies of the alleles e2, e3, and e4 did not differ between the two groups.

Serum low density lipoprotein cholesterol concentration was higher in subjects with the phenotypes E3/ $3, \mathrm{E} 4 / 4$, or E4/3 compared with that in subjects with the phenotypes E2/2 or E2/3. Otherwise serum lipid and lipoprotein concentrations did not differ among the apolipoprotein E phenotypes (table III). Serum total cholesterol and apolipoprotein B concentrations tended to be higher in subjects with the phenotypes E4/ 4 or E4/3 than in the other groups, but the difference did not reach significance. With respect to clinical characteristics and metabolic control of diabetes the apolipoprotein E phenotype groups did not differ significantly from each other (table IV). However, the

TABLE I-Characteristics of control subjects and subjects with noninsulin dependent diabetes

\begin{tabular}{lccc}
\hline & & & \\
\cline { 3 - 4 } & Controls & $\begin{array}{c}\text { Diabetic } \\
\text { men }\end{array}$ & p Value \\
\hline No of Men & 64 & 138 & \\
Mean (SD) age (years) & $54(1)$ & $56(1)$ & $\mathrm{NS}$ \\
Mean (SD) body mass index $\left(\mathrm{kg} / \mathrm{m}^{2}\right)$ & $25 \cdot 5(0 \cdot 3)$ & $27 \cdot 7(0 \cdot 3)$ & $<0 \cdot 001$ \\
Mean (SD) fasting blood glucose $(\mathrm{mmol} / \mathrm{l})$ & $5 \cdot 4(0 \cdot 1)$ & $10 \cdot 8(0 \cdot 3)$ & $<0 \cdot 001$ \\
Mean (SD) glycated haemoglobin (\%) & $7 \cdot 7(0 \cdot 2)$ & $9 \cdot 6(0 \cdot 2)$ & $<0 \cdot 001$ \\
No(\%) of smokers & $18(29)$ & $37(27)$ & $\mathrm{NS}$ \\
No(\%) with hypertension & $13(20)$ & $85(62)$ & $<0 \cdot 01$ \\
No(\%) physically active & $45(70)$ & $68(49)$ & $<0 \cdot 05$ \\
& & &
\end{tabular}

TABLE II-Apolipoprotein $E$ phenotypes and gene frequencies in control and diabetic men

\begin{tabular}{lcc}
\hline & Control (n=64) & $\begin{array}{c}\text { Non-insulin dependent } \\
\text { diabetes }(\mathbf{n}=138)\end{array}$ \\
\hline $\begin{array}{l}\text { Phenotype }(\mathrm{No}(\%)): \\
\text { E2/2 }\end{array}$ & $2(3)$ & $2(1)$ \\
E2/3 & $4(6)$ & $15(11)$ \\
E3/3 & $46(72)$ & $85(62)$ \\
E4/3 & $10(16)$ & $32(23)$ \\
E4/4 & $2(3)$ & $4(3)$ \\
Gene frequency: & & \\
e2 & $0 \cdot 063$ & $0 \cdot 069$ \\
e3 & $0 \cdot 828$ & $0 \cdot 786$ \\
e4 & $0 \cdot 109$ & $0 \cdot 145$ \\
\hline
\end{tabular}


TABLE III-Mean $(S D)^{\star}$ serum lipid, lipoprotein, and apolipoprotein concentrations in men with noninsulin dependent diabetes by apolipoprotein $E$ phenotype

\begin{tabular}{|c|c|c|c|c|}
\hline & $\mathrm{E} 2 / 2, \mathrm{E} 2 / 3(\mathrm{n}=17)$ & E $3 / 3(n=85)$ & $\mathrm{E} 4 / 3, \mathrm{E} 4 / 4(\mathrm{n}=36)$ & $\begin{array}{c}\text { Analysis of } \\
\text { variance (p } \\
\text { value) }\end{array}$ \\
\hline \multicolumn{5}{|l|}{ Cholesterol $(\mathrm{mmol} / \mathrm{l})$ : } \\
\hline Total & $6.33(1.94)$ & $6.69(1 \cdot 27)$ & $6 \cdot 78(1.53)$ & NS \\
\hline High density lipoprotein & $1 \cdot 11(0 \cdot 27)$ & $1 \cdot 16(0 \cdot 31)$ & $1.08(0.29)$ & NS \\
\hline Low density lipoprotein & $3.59(0.94)$ & $4.26(0.94) t$ & $4 \cdot 15(1.06) \dagger$ & 0.038 \\
\hline Very low density lipoprotein & $1.63(1.42)$ & $1.28(1.01)$ & $1.55(1.30)$ & NS \\
\hline \multicolumn{5}{|l|}{ Triglycerides $(\mathrm{mmol} / \mathrm{l})$ : } \\
\hline Total & $2.07(1.31$ to $2 \cdot 83)$ & $2.07(1.78$ to 2.36$)$ & $2.10(1.63$ to 2.57$)$ & NS \\
\hline High density lipoprotein & $0.13(0.08)$ & $0.15(0.08)$ & $0.13(0.07)$ & NS \\
\hline Low density lipoprotein & $0.35(0 \cdot 16)$ & $0.40(0.22)$ & $0.37(0.21)$ & NS \\
\hline Very low density lipoprotein & $1.57(0.71$ to 2.51$)$ & $1.51(0.85$ to 1.85$)$ & $1.60(1.08$ to $2 \cdot 12)$ & NS \\
\hline \multicolumn{5}{|c|}{ Apolipoprotein $(\mathrm{g} / \mathrm{l})$ : } \\
\hline AI & $0 \cdot 76(0 \cdot 10)$ & $0 \cdot 76(0 \cdot 13)$ & $0.75(0 \cdot 15)$ & NS \\
\hline B & $0.90(0.30)$ & $1.01(0.36)$ & $1.06(0.34)$ & NS \\
\hline
\end{tabular}

* Geometric means ( $95 \%$ confidence intervals) are presented for total and very low density lipoprotein triglycerides. $\mathrm{tp}<0 \cdot 05(\mathrm{E} 4 / 3, \mathrm{E} 4 / 4, v \mathrm{E} 2 / 2, \mathrm{E} 2 / 3$ or $\mathrm{E} 3 / 3 v \mathrm{E} 2 / 2, \mathrm{E} 2 / 3)$.

TABLE IV-Clinical characteristics and metabolic control for men with non-insulin dependent diabetes by apolipoprotein $E$ phenotype

\begin{tabular}{|c|c|c|c|c|}
\hline & $\mathrm{E} 2 / 2, \mathrm{E} 2 / 3(\mathrm{n}=17)$ & $E 3 / 3(n=85)$ & $E 4 / 3, E 4 / 4(n=36)$ & $\begin{array}{c}\text { Analysis of } \\
\text { variance (p } \\
\text { value) }\end{array}$ \\
\hline Mean (SD) age (years) & $55(1)$ & $56(1)$ & $56(1)$ & NS \\
\hline Mean (SD) body mass index $\left(\mathrm{kg} / \mathrm{m}^{2}\right)$ & $28 \cdot 1(0 \cdot 9)$ & $27 \cdot 7(0 \cdot 4)$ & $28 \cdot 1(0 \cdot 7)$ & NS \\
\hline Mean (SD) fasting blood glucose $(\mathrm{mmol} / \mathrm{l})$ & $11 \cdot 3(1 \cdot 0)$ & $10 \cdot 7(0 \cdot 4)$ & $10 \cdot 3(0 \cdot 5)$ & NS \\
\hline Mean (SD) glycated haemoglobin (\%) & $9 \cdot 2(0.5)$ & $9 \cdot 6(0 \cdot 2)$ & $9.5(0.3)$ & NS \\
\hline No $(\%)$ of current smokers & $3(18)$ & $25(29)$ & $8(22)$ & NS \\
\hline No $(\%)$ with hypertension & $10(59)$ & $51(60)$ & $25(69)$ & NS \\
\hline No (\%) physically active & $13(76)$ & $41(48)$ & $18(50)$ & NS \\
\hline
\end{tabular}

actual percentages of current smokers and physically active subjects were quite different among the groups.

Table $\mathrm{V}$ shows the prevalence of coronary heart disease by different criteria according to the apolipoprotein $\mathrm{E}$ phenotypes in men with non-insulin dependent diabetes. The prevalences of coronary heart

TABLE $\mathrm{v}-$ Prevalence of coronary heart disease by different criterio according to apolipoprotein $E$ phenotype in non-insulin dependent diabetic men

\begin{tabular}{lccc}
\hline & $\begin{array}{c}\text { No } \\
\text { of men }\end{array}$ & Prevalence (\%) & $\begin{array}{c}95 \% \text { Confidence } \\
\text { interval (\%) }\end{array}$ \\
\hline Myocardial infarction: & & & \\
E2/2, E2/3 & 2 & 12 & 7 to 17 \\
E3/3 & 15 & 18 & 12 to 24 \\
E4/4, E4/3 & 9 & 25 & 18 to 32 \\
Ischaemic electrocardiographic charges: & & \\
E2/2, E2/3 & 6 & 35 & 27 to 43 \\
E3/3 & 33 & 39 & 31 to 47 \\
E4/4, E4/3 & 18 & 50 & 42 to 58 \\
Angina pectoris: & & & \\
E2/2, E2/3 & 8 & 47 & 39 to 55 \\
E3/3 & 35 & 41 & 33 to 49 \\
E4/4, E4/3 & 25 & 69 & 62 to 75 \\
Any evidence of coronary heart disease: & & \\
E2/2, E2/3 & 9 & 53 & 51 to 71 \\
E3/3 & 49 & 58 & 50 to 66 \\
E4/4, E4/3 & 29 & 81 & 75 to 87 \\
\hline
\end{tabular}

disease in control subjects were too low to allow statistical analysis. The prevalences of definite myocardial infarction and ischaemic electrocardiographic changes were highest in the subjects with the phenotypes $\mathrm{E} 4 / 4$ or $\mathrm{E} 4 / 3$ ( $25 \%$ and $50 \%$, respectively), although the difference between the phenotype groups was not significant. Angina pectoris was found in $69 \%$ (25) of subjects with the phenotypes E4/4 or E4/3 ( $p=0.005$ compared with other phenotypes) compared with $41 \%$ (35) of subjects with the phenotype E3/3 and $47 \%$ (six) of those with phenotypes E2/2 or E2/3. Similarly, the prevalence of simultaneous presence of angina pectoris and ischaemic electrocardiographic changes was higher (42\%) in subjects with phenotypes $\mathrm{E} 4 / 4$ or $\mathrm{E} 4 / 3$ than in those with other phenotypes (E3/3 22\%; E2/2, E2/3 29\%; p=0.038). Overall, the prevalence of any evidence of coronary heart disease among the subjects with the phenotypes E4/4 or E4/3 was $81 \%$ ( $\mathrm{p}=0.011$ compared with other phenotypes), $58 \%$ in subjects with the phenotype $\mathrm{E} 3 / 3$, and $53 \%$ in subjects with phenotypes E2/2 or E2/3.

\section{Discussion}

The apolipoprotein E phenotypes E4/4 and E4/3 were strongly associated with coronary heart disease in non-insulin dependent diabetic men. This is a new finding which could explain, at least in part, the increased risk of coronary heart disease in patients with non-insulin dependent diabetes.

The evidence that the apolipoprotein $\mathrm{E}$ polymorphism modulates susceptibility to atherosclerotic vascular disease in people without diabetes is controversial. Some studies, ${ }^{2426}$ but not all, ${ }^{27}$ have shown a significant increase in the frequency of the e4 allele in the survivors of myocardial infarction or in the patients with angiographically verified coronary heart disease. Furthermore, the allele e 4 has been observed to increase the risk of myocardial infarction at an early age. ${ }^{28}$ These studies, however, have not included representative samples of non-diabetic population but highly selective groups of patients with established coronary heart disease. Differences in the prevalences of the e4 allele and coronary heart disease between populations also support the role of the e4 allele as a risk indicator for atherosclerosis. The Finns have exceptionally high prevalences of the e4 allele $^{2029}$ and coronary heart disease ${ }^{7}$ whereas in the Chinese ${ }^{30}$ and Japanese $^{31}$ populations the e4 allele is relatively uncommon, as is coronary heart disease.

\section{ROLE OF E4 ALLELE}

Why should people with non-insulin dependent diabetes be particularly susceptible to coronary heart disease if they happen to fall into the e4 allele category? Firstly, relatively high frequency of the apolipoprotein $E$ phenotypes E4/4 and E4/3 in people with non-insulin dependent diabetes could lead to an increased risk of coronary heart disease. The distribution of the apolipoprotein $\mathrm{E}$ phenotypes in subjects with and without diabetes, however, was similar in our study and some other studies. ${ }^{32-34}$

Secondly, the risk for coronary heart disease could be related to the impact of the apolipoprotein $E$ phenotypes on serum lipid and lipoprotein concentrations. Apolipoprotein $\mathrm{E}$ participates in the conversion of very low density lipoprotein remnants to low density lipoprotein, and this metabolic pathway is particularly effective in subjects with the e4 allele, which might result in a higher rate of production of low density lipoprotein in these subjects. ${ }^{135}$ Furthermore, a high density lipoprotein subfraction containing apolipoprotein $\mathrm{E}$ is considered to play an important part in the reverse cholesterol transport, ${ }^{36}$ although the underlying mechanisms are poorly understood. Also subjects with the e 4 allele have higher total and low density lipoprotein cholesterol concentrations, ${ }^{2-5}$ which increase the risk of coronary heart disease in the nondiabetic population.

High low density lipoprotein concentrations in people with the e4 allele seem to be related to the particularly effective absorption of cholesterol in these subjects, ${ }^{29}$ which may be one explanation for the differences in low density lipoprotein concentrations among people with the various apolipoprotein $\mathrm{E}$ phenotypes. We found that total and low density lipoprotein cholesterol concentrations were higher in diabetic subjects with the $\mathrm{e} 4$ allele than in subjects with the $\mathrm{e} 2$ allele, confirming the findings of some previous studies. ${ }^{32}{ }^{33}$ The low density lipoprotein cholesterol concentration of the subjects with phenotype E3/3 (62\% of the study population) was similar to that in subjects with the $\mathrm{e} 4$ allele and higher than that in the 
subjects with the e2 allele. But subjects with the E3/3 allele and non-insulin dependent diabetes still had a lower rate of coronary heart disease manifestations than those with the 44 allele.

No differences in other cardiovascular risk factors (smoking, hypertension, obesity, physical activity) were found between the different apolipoprotein $\mathrm{E}$ phenotypes (table IV), indicating that the susceptibility to corgnary heart disease cannot be explained by these classic cardiovascular risk factors alone. Thus some additional mechanism related to the apolipoprotein $\mathbf{E}$ phenotype must be considered. Firstly, the modulation of lipoprotein metabolism by apolipoprotein E may not necessarily reflect the measured serum lipid and lipoprotein concentrations. Secondly, various mechanisms not related to the regulation of lipid and lipoprotein metabolism should also be considered. There is evidence that apolipoprotein $\mathrm{E}$ is involved in the immune system and tissue regeneration, which might indicate that it could also have a direct action on the atherogenic process at the cellular level in the arterial wall..$^{37-39}$

CONCLUSIONS

Although the mechanisms for the association between coronary heart disease and the apolipoprotein E phenotypes in non-insulin dependent diabetes remain unexplained, our findings suggest that the apolipoprotein phenotypes $E 4 / 4$ and $E 4 / 3$ should be considered as important risk indicators for coronary heart disease in people with non-insulin dependent diabetes. The confirmation of apolipoprotein $\mathrm{E}$ polymorphism as an important contributory factor for coronary heart disease in non-insulin dependent diabetes warrants long term follow up studies based on representative population cohorts.

This work was supported by the Medical Council of the Academy of Finland, the Sigrid Juselius Foundation, and the Nordic Insulin-Fund. We thank Raija Tolkkinen and Saija Kortetjärvi for technical help and Dr Christian Ehnholm for supplying the human apolipoprotein $\mathrm{E}$ antibody.

1 Davignon J, Gregg RE, Sing CF. Apolipoprotein E polymorphism and atherosclerosis. Anteriosclerosis 1988;8:1-21.

2 Utermann G, Kindermann I, Kaffarnik H, Steinmetz A. Apolipoprotein E Utermann G, Kindermann I, Kaffarnik H, Steinmetz A. A
phenotypes and hyperlipidemia. Hum Genet 1984;65:232-6.

3 Assmann G, Schmitz G, Menzel HJ, Schultz H. Apolipoprotein E polyAssmann G, Schmitz G, Menzel HJ, Schultz H. Apolipopro
morphism and hyperlipidemia. Clin Chem 1984;30:641-3.

4 Leren TP, Borresen A-L, Hjermann I, Leren P, Berg K. Increased frequency of the apolipoprotein E-4 isoform in male subjects with multifactorial hypercholesterolemia. Clin Genet 1985;27:458-62.

5 Sing CF, Davignon J. Role of apolipoprotein E polymorphism in determining normal plasma lipid and lipoprotein variation. Am $\mathcal{F}$ Hum Genet 1985;37 268-85.

6 Pyörälä $K$, Laakso $M$, Uusitupa $M$. Diabetes and atherosclerosis: an epidemiological view. Diabetes Metab Rev 1987;3:463-524.

7 Pyörälä K, Salonen JT, Valkonen T. Trends in coronary heart disease mortality and morbidity and related factors in Finland. Cardiology 1985;72 35-51.

8 Laakso M, Rönnemaa T, Pyörälä K, Kallio V, Puukka P, Penttilä I. Atherosclerotic vascular disease and its risk factors in non-insulin-dependen diabetic and nondiabetic subjects in Finland. Diabetes Care 1988;11:449-63.

9 World Health Organisation Expert Committee on Diabetes Mellitus. Second report. WHO Tech Rep Ser 1980:646.

report. Wlackburn H, Gillum RF, Prineas RJ. Cardiovascular survey methods.
10 Rose G, Black Rose G, Blackburn H, Gillum RF, Prineas RJ. Cardio
2nd ed. Geneva: World Health Organisation, 1982.
11 World Health Organisation. Proposal for the multinational monitoring of trends and determinants in cardiovascular disease and protocol (MONICA project). Geneva: WHO (WHO/MNC/82.1, Rev 1)

12 Penttilä I, Voutilainen E, Laitinen P, Juutilainen P. Comparison of different analytical and precipitation methods for the direct estimation of serum highdensity lipoprotein cholesterol. Scand f Clin Lab Invet 1981;41:353-60

13 Havel RJ, Eder HA, Bragdon HJ. The distribution and chemical composition of ultracentrifugally separated lipoproteins in human serum. $\mathcal{J}$ Clin Invest 1955;34:1345-53.

14 Laakso M, Voutilainen E, Pyörälä K, Sarlund H. Association of low serum $\mathrm{HDL}$ and $\mathrm{HDL}_{2}$ cholesterol with coronary heart disease in noninsulin dependent diabetics. Arteriosclerosis 1985;5:653-8.

15 Laakso M, Pyörälä K, Voutilainen E, Marniemi J. Plasma insulin and serum lipids and lipoproteins in middle-aged non-insulin-dependent diabetic and non-diabetic subjects. Am F Epidemiol 1987;125:611-21.

16 Siedel J, Schlumberger $\mathrm{H}$, Klose S, Ziegenhorn J, Wahlefeld AW. Improved reagent for the enzymatic determination of serum cholesterol. $\mathcal{f}$ Clin Chem Clin Biochem 1981;19:838-9.

17 Riepponen P, Marniemi J, Rautoja T. Immunoturbidometric determination of apolipoproteins A-I and B in serum. Scand J Clin Lab Invest 1987;47:739. 44.

18 Jauhiainen M, Laitinen M, Marniemi J, Liippo K, Pentrilä I, Hietanen E. Preparation of soluble apolipoproteins A-I, B, and C-II by a chromatoPreparation of soluble apolipoproteins A-I, B, and C-II by a chromato-
focusing column method, and evaluation of their concentrations in serum in focusing column method, and evaluation of their
pulmonary disease. Clin Chem 1983;29:1731-5.

19 Menzel H-J, Utermann G. Apolipoprotein E phenotyping from serum by western blotting. Electrophoresis 1986;7:492-4.

20 Ehnholm C, Lukka M, Kuusi T, Nikkilä E, Utermann G. Apolipoprotein E polymorphism in the Finnish population: gene frequencies and relation to lipoprotein concentrations. $\mathcal{F}$ Lipid Res 1986;27:227-35.

21 Faber OK, Binder C. C-peptide response to glucagon: a test for the recidual $\beta$-cell function in diabetes mellitus. Diabetes 1977;26:605-10.

22 Heding LG. Radioimmunological determination of human C-peptide in serum. Diabetologia 1975;11:541-8.

23 Madsbad S, Alberti KGGM, Binder C, Brurin JM, Faber OK, Krarup T, et al. Role of recidual insulin secretion in protecting against ketoacidosis in insulin dependent diabetics. BMF 1979;ii:1257-9.

24 Cumming AM, Robertson F. Polymorphism at the apo $\mathrm{E}$ locus in relation to risk of coronary artery disease. Clin Genet 1984;25:310-3.

25 Menzel H-J, Kladetzky R-G, Assmann G. Apolipoprotein E polymorphism and coronary artery disease. Arteriosclerosis 1983;3:310-5.

26 Kuusi T, Nieminen M, Ehnholm C, Yki-Jarvinen H, Valle M, Nikkila EA, et al Apoprotein $\mathrm{E}$ polymorphism and coronary artery disease. Increased prevalence of apolipoprotein E-4 in angiographically verified coronary patients. Arteriosclerosis 1989;9:237-41

27 Utermann G, Hardewig A, Zimmer F. Apo E phenotypes in patients with myocardial infarction. Hum Genet 1984;65:237-41.

28 Lenzen HJ, Assmann G, Buchwalsky R, Schulte H. Association of apolipoprotein E polymorphism, low density lipoprotein cholesterol, and coronary artery disease. Clin Chem 1986;32:778-81.

29 Kesäniemi YA, Ehnholm C, Miettinen TA. Intestinal cholesterol absorption efficiency in man is related to apolipoprotein E phenotype. $\mathcal{J}$ Clin Invest 1987;80:578-81.

30 Wang $\mathrm{K}$. Studies of human apolipoprotein $\mathrm{E}$ genetic isoforms and their phenotypes among the Chinese population. Acta Acadanuae Medicineae Sinicae 1986;8:198.

31 Eto $M$, Watanabe $K$, Ishii $K$. Reciprocal effects of apolipoprotein $E$ alleles (e2 and e4) on plasma lipid levels in normolipidemic subjects. Clin Genet 1986;29:477-84

32 Eto $M$, Watanabe $\mathrm{K}$, Iwashima $\mathrm{Y}$, Morikawa A, Oshima E, Sekiguchi M, et al. Apolipoprotein $\mathrm{E}$ polymorphism and hyperlipemia in type II diabetics. Diabetes 1986;35:1374-82.

33 Eto $M$, Watanabe K, Iwashima Y, Morikawa A, Chonan N, Oshima E, et al. Increased frequency of apolipoprotein e4 allele in type II diabetes with hypercholesterolemia. Diabetes 1987;36:1301-6.

34 Imari $Y$, Koga S, Ibayashi $H$. Phenotypes of apolipoprotein $E$ and abnormalities in lipid metabolism in patients with diabetes mellitus. Metabolism 1988;37:1134-8.

35 Gregg RE, Zech LA, Schaefer EJ, Brewer HB Jr. Type III hyperlipoproteinemia: defective metabolism of an abnormal apolipoprotein E. Science 1981;211:584-5.

36 Basu SK, Ho YK, Brown MS, Bilheimer DW, Anderson RGW, Goldstein JL. Biochemical and genetic studies on the apolipoprotein $\mathrm{E}$ secreted by mouse macrophages and human monocytes. $\mathcal{F}$ Biol Chem 1982;257:9788-95.

37 Hui DY, Harmony JA, Innerarity TL, Mahley R. Immunoregulatory plasma lipoproteins. Role of apoprotein $\mathrm{E}$ and apoprotein B. F Biol Chem 1980;255:11775-81.

38 Pepe MG, Curtiss LK. Apolipoprotein E is a biologically active consitituent of the normal immunoregulatory lipoprotein, LDL-In. $\mathcal{F}$ Immunol 1986;136: 3716-23.

39 Mahley RW. Apolipoprotein E: Cholesterol transport protein with expanding role in cell biology. Science 1988;240:622-30.

(Accepted 16 August 1991) 